\title{
Finite element simulation and regression modeling of machining attributes on turning AISI 304 stainless steel
}

\author{
A. Mathivanan ${ }^{1}$, M.P. Sudeshkumar ${ }^{2}$, R. Ramadoss ${ }^{3}$, Chakaravarthy Ezilarasan ${ }^{4,}$, Ganesamoorthy Raju ${ }^{4}$, \\ and V. Jayaseelan ${ }^{5}$ \\ ${ }^{1}$ Department of Mechanical Engineering, SRM Institute of Science and Technology (SRM IST) Ramapuram Campus, Chennai \\ 600089 , India \\ ${ }^{2}$ Department of Mechanical Engineering, Shreenivasa Engineering College, Dharmapuri, 635301, Tamil Nadu, India \\ 3 Department of Mechanical engineering, Easwari Engineering College, Chennai 600089, India \\ ${ }^{4}$ Center for Materials Research, Chennai Institute of Technology, Chennai 600069, India \\ ${ }^{5}$ Department of Mechanical Engineering, Prathyusha Engineering College, Chennai 602025, India
}

Received: 9 June 2021 / Accepted: 13 July 2021

\begin{abstract}
To-date, the usage of finite element analysis (FEA) in the area of machining operations has demonstrated to be efficient to investigate the machining processes. The simulated results have been used by tool makers and researchers to optimize the process parameters. As a 3D simulation normally would require more computational time, 2D simulations have been popular choices. In the present article, a Finite Element Model (FEM) using DEFORM 3D is presented, which was used to predict the cutting force, temperature at the insert edge, effective stress during turning of AISI 304 stainless steel. The simulated results were compared with the experimental results. The shear friction factor of 0.6 was found to be best, with strong agreement between the simulated and experimental values. As the cutting speed increased from $125 \mathrm{~m} / \mathrm{min}$ to $200 \mathrm{~m} / \mathrm{min}$, a maximum value of $750 \mathrm{MPa}$ stress as well as a temperature generation of $650{ }^{\circ} \mathrm{C}$ at the insert edge have been observed at rather higher feed rate and perhaps a mid level of depth of cut. Furthermore, the Response Surface Methodology (RSM) model is developed to predict the cutting force and temperature at the insert edge.
\end{abstract}

Keywords: AISI 304 stainless steel / DEFORM 3D / simulation / cutting force / temperature at insert edge / effective stress

\section{Introduction}

One of the most important machining operations is turning, which is normally deployed in the aircraft manufacturing and automotive industries, among other areas. Conventional turning is still been widely used during machining in the automotive industry, despite the advancement of modern machining techniques. This seems to be due to the lower cost and flexibility of use. Machining performance on the parts in manufacturing industries should be reliable with good quality. The prediction of the machining attributes in advance would reduce the machining cost resulting from unidentified level of machining parameters; hence a suitable predictive model is required to predict the machining attributes [1]. Since the precision of the simulated outcome is entirely dependent on the process variables, it is important to understand

\footnotetext{
* e-mail: ezhilshriram.c@gmail.com
}

the effects of different levels of process variables employing appropriate statistical models on turning any materials [2].

The chip formation during machining operation is complex in nature and there is need to simulate the machining process and in DEFORM 3D, the simulation takes weeks to complete. As a result, in the simulation phase, an attempt will be made to optimize the simulation dimensions. The machining performances of coated and uncoated drill are studied in drilling AISI 1050 steel and they have observed that the coated drill produced minimum tool wear than uncoated drill [3].

Tzotzis et al. [4] created a finite element model to predict the thrust force in drilling of Al7075-T6 using solid carbide drill. Further, they have also developed a predictive model to predict the thrust force using response surface methodology (RSM). The percentage error of $5.9 \%$ was observed among the developed models by FEA and RSM. The simulated thrust force by DEFORM 3D results in good agreement with the experimental results in drilling 
of Al7075-T6. In their work, the drill tip was considered stiff with a coarse mesh of 20,000 and in another study, a circular cutting tool and fine mesh with 10:1 ratio was used.

$\mathrm{Yu} \mathrm{Su}$ et al. [5] have optimized the machining parameters using grey relational modeling and response surface methodology in turning AISI 304 stainless steel. They have reported the optimum condition of process parameters to achieve minimum surface roughness such as, depth of cut $-2.2 \mathrm{~mm}$, feed rate $-0.15 \mathrm{~mm} / \mathrm{rev}$ and cutting speed $-90 \mathrm{~m} / \mathrm{min}$ in turning AISI 304 stainless steel. Elkaseer et al. [6] investigated the chip formation and surface generation in hard turning the stainless steel 316. They have simulated the chipping process by using finite element method and also validated with experimental results. A good agreement was found among experiments and FEM results and they have commented that, the simulated results by FEM would be used to identify the optimum machining process.

Leksycki et al. [7] have observed the cutting force as well as chip in turning of 17-4 PH stainless steel. The cutting force was simulated using finite element analyses and the work material was described by means of the Johnson Cook flow stress model. Finally, they have reported that, at low feed rates and depth of cut, the cutting force was decreased. Yingshuai et al. [8] have performed turning operations on 304 stainless steel using both traditional and ultrasonic aided turning techniques. The impact of conventional turning (CT) was compared with ultrasonic assisted turning (UAT) in terms of tool wear, surface quality, and cutting power. They have claimed that, the ultrasonic amplitude was identified as significant factor followed by cutting speed, depth of cut and feed rate in UAT of ASS 304 steel. Sadeghifar et al. [9] have developed optimal machining parameters to optimize the machining characteristics in hard turning of steel and also they have developed a predictive model by FEA to predict the thrust force, temperature at the cutting zone and residual stresses. The predicted results of the responses were compared with experimental results for validation purpose and the predicted results were found to be in good agreement with experiment values. Further, they have also carried out a hybrid optimization combining the sequential quadratic programming and genetic algorithm for resolving the optimization problems to find out optimum machining parameters and geometry of the tool.

Boing et al. [10] evaluated the wear mechanism of PVD and CVD coated insert in turning the AISI 304 steel. They have also attempted to identify/track the form of wear as well as the coating material's damage. Abrasion, detachment between coating layers, propagation, creation of crack networks, crack nucleation, delamination were found in the CVD coated inserts. The high deformation rates and abrasion wear near the cutting edge were seen in the PVD coated inserts. It has caused the creation of cracks throughout the coating and has weakened the bond. Parid et al. [11] have simulated the chip morphology using DEFORM 3D in turning AISI 316 steel and they have reported that, the increment of chip segmentation and chip serration was happened owing to mainly increase in the level of cutting speed and feed rate respectively.
Agmell et al. [12] have simulated the principal and effective stress distribution in turning AISI 4140 steel by finite element analysis considering different tool geometries. The simulated stress values were compared with experimental results and they have reported that, the simulated stress values found to be close to the experimental values. Further, they have observed reduction in the principal stress when the micro-geometry tool was used. Sadeghifar et al. [13] have reviewed the finite element orthogonal operations and the impact of the machining parameters on the machining characteristics such as tool wear, cutting force, and surface roughness. They have commonly observed that, additional efforts are needed due to the increased complexity of the machining process, caused due to nonlinearities in the material and machining process.

Yildiz et al. [14] have studied the impact of stress on thrust force and torque in drilling AISI 1050 using TiAlN/ TiN coated and uncoated drill. Further, they have simulated the drilling operations using DEFORM 3D to investigate the relations among machining parameters and stresses. They have reported that stresses were seen majorly around the cutting edge and on the helical shaped flute. Nur et al. [15] have performed turning operations on AISI 316L steel in dry condition and they have studied the impact of machining parameters on cutting force, surface roughness, tool life and cutting power. The feed rate was found to be significant on surface roughness and cutting forces followed by cutting speed and the life of the tool was decreased as the level of cutting speed and feed rate increased.

Ay [16] looked into the effects of machining parameters on surface roughness and cutting force while turning AISI 304L stainless steel and discovered the best machining conditions. They have stated that, the wiper insert have achieved better efficiency well then PVD TiAlN-coated conventional. The whale optimization algorithm was used by Tanvit et al. [17] to optimise the machining parameters in turning the stainless steel 304. Further, they have investigated the impact of machining parameters on cutting forces, peak tool temperature, surface roughness and material removal rate. Zhou et al. [18] have simulated the machining performances such as surface roughness, cutting force, temperature at the cutting edge and residual stresses in turning aluminum-silicon piston alloy ZL109 using DEFORM 3D. The Johnson-Cook (JC) constitutive model was used to define the workpiece. The simulated values were found to be close agreement with experimental results.

From the literatures, it was identified that, the simulation of the responses such as cutting force, temperature generation at insert edge, effective stress, strain etc., was carried out using DEFORM 3D in turning of many materials. However, there was lack of study on the simulation of the responses in turning the AISI 304 steel. Therefore, in the present work the simulation of the cutting force, temperature generation at insert edge and effective stress are carried out using DEFORM 3D. The simulated values are validated with the experimental results. In addition, the response surface methodology was used to develop a model to predict the responses. 
Table 1. Process parameters and their levels.

\begin{tabular}{lllll}
\hline Process Parameters & Symbol & L1 & L2 & L3 \\
\hline Cutting speed $(\mathrm{m} / \mathrm{min})$ & $\mathrm{S}$ & 125 & 175 & 200 \\
Feed rate $(\mathrm{mm} / \mathrm{rev})$ & $\mathrm{f}$ & 0.10 & 0.20 & 0.30 \\
Depth of cut $(\mathrm{mm})$ & $\mathbf{a}_{\mathbf{p}}$ & 0.25 & 0.40 & 0.60 \\
\hline
\end{tabular}

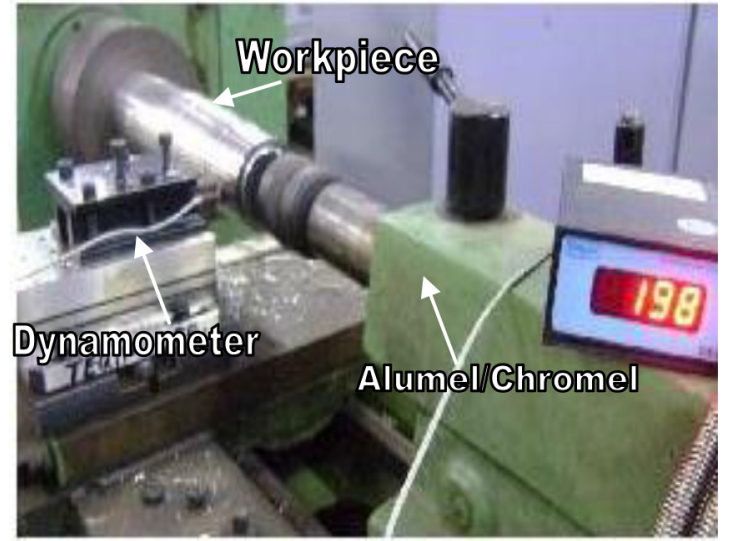

Fig. 1. Experimental set-up.

\section{Materials and methods}

Turning tests were carried out in a dry setting on the center lathe. The depth of cut, feed rate and cutting speed were considered as machining parameters and is summarized in Table 1. The parameter levels were chosen based on the literature and tool maker recommendations. Figure 1 portrays the experimental setup. AISI 304 stainless steel was used as work material, which contains the following components (in weight percentages): Cr-18-20 percent, Fe-67-71 percent, Ni-8- 12 percent, S-0.030 percent, P-0.045 percent, N-0.10 percent, Mn-2 percent, Si-0.75 percent, and C-0.08 percent. Implementing PVD TiAlN coated cemented carbide ISO inserts, that work piece has been turned for experimental studies. A $\mathrm{L}_{9}$ orthogonal array was used to perform the experiment. The cutting force was calculated using a 3-component Kistler (Model 9257B) piezo-electric dynamometer. A thermocouple made of alumel/chrome was used to test the temperature at the insert edge.

\section{Simulation and analysis operations}

Data such as process parameters and conditions, insert material, environment temperature, work piece materials, cutting speed, depth of cut, feed rate, and other assumptions were used as input data in the modeling and simulation. The curved shape of the work piece was considered and perfectly plastic, as shown in Figure 2. Figure 3 depicts the DEFORM 3D steps used to simulate machining operations. The DEFORM 3D library was used to pick the work piece and insert, with tungsten carbide

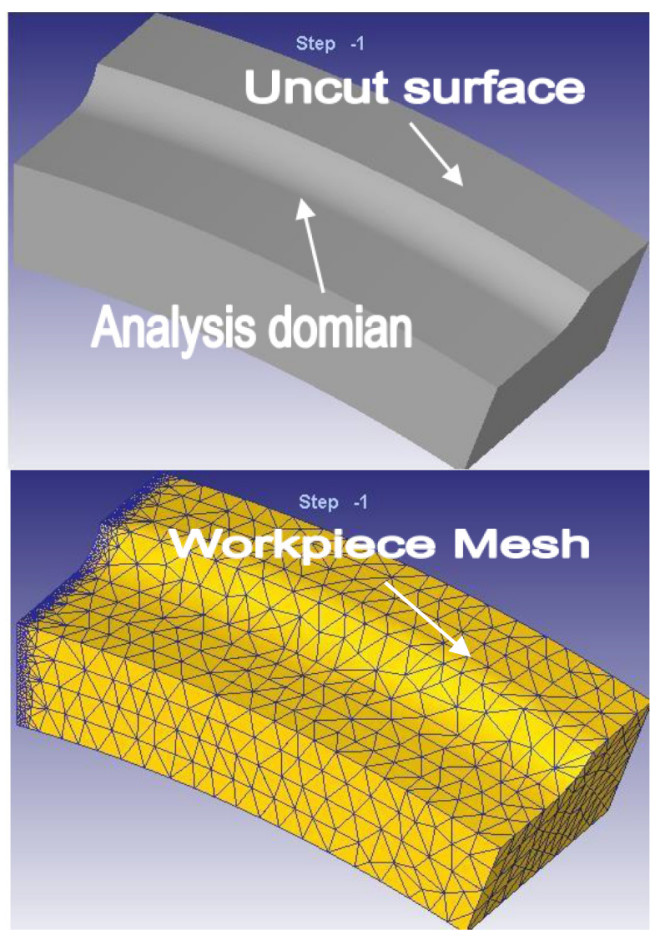

Fig. 2. Work piece shape: (a) without mesh; (b) with mesh.

serving as the insert material. Figure 4 depicts the insert. Figure 5 depicts the initial tool, work component's mesh configuration and isometric view ( $X$ is the feed direction, $Y$ is the cutting direction, and $Z$ is the depth of cut direction).The impact of process variables on machining characteristics such as temperature at insert edge, cutting force, effective tension, and effective stress was addressed. The simulations were carried out using the $\mathrm{L}_{9}$ array. Table 2 lists the assumptions that were used in this study.

The friction along tool-work material interface in the simulation during the machining process is complex and it depends on the sliding velocity and pressure. The contact conditions at the interface would affect the thermal and mechanical characteristics [19]. The friction in between the tool-work interface is influenced by cutting temperature generation, tool wear, and chip formation etc. The friction coefficient may be mentioned as a constant one, a function of time/interface pressure in-between tool - work. The shear friction factor values in the range of $0.5-0.7$ are considered to simulate the cutting force, temperature at insert edge and the simulated values are compared with experimental results. The frictional force in the Coulomb law model is given in the equation:

$$
f_{s}=\mu p,
$$

where $f_{s}$ is the frictional stress and $p$ is the interface pressure between two bodies [1].

The shear friction factor in the range of $0.4,0.5$ and 0.6 are used to predict the cutting force, and temperature at insert edge. The simulated values with 0.6 shear friction factor in turning AISI 304 steel are found to be close with the experimental results. 
- Selection of unit system (English, International Standard system)

- Machining type (turning, milling, boring, drilling)

- Process setup (Surface speed (v), Rotational speed (rpm)

- Process condition (Temperature, Convection coefficient, Tool-Work piece-shear friction factor, heat transfer coefficient)

- Tool setup (loads an existing tool from library/defines a new tool)

- Tool holder setup (load from tool library/create new holder)

- Tool mesh generation

- View Insert BCC

- Work piece setup (Work piece type: plastic/Elasto-plastic)

- Work piece shape (curved model/Simplified model)

- View work piece boundary condition

- Work piece material setup (load from library/Import material from file/create new material)

- Simulation (lagrangian Incremental/Steady state machining/Steady state extrusion)

Fig. 3. Steps in DEFORM 3D.

Table 2. Basic Assumption.

\begin{tabular}{lll}
\hline S. no & Assumptions & Values \\
\hline 1 & Shear friction factor & 0.7 \\
2 & Element type & Tetrahedral \\
3 & Mesh type & Fine Mesh, \\
4 & Node & 10 nodes \\
5 & Relative mesh type (tool) & 45000, \\
6 & Relative mesh type (work) & 35000, \\
7 & Work piece material & AISI 304, \\
8 & Work material type & Plastic, isotropic, \\
9 & Work piece shape & Curved, \\
10 & Tool material & Carbide \\
11 & Coolant & No, \\
12 & Environment temperature & $20{ }^{\circ} \mathrm{C}$, \\
13 & Convection coefficient & 0.02 \\
14 & Heat transfer coefficient & 45, \\
15 & Number of simulation steps & 7500, \\
16 & Step increment to save & 25 \\
17 & Arc angle to cut & 20. \\
\hline
\end{tabular}

\section{Analysis of variance}

In addition, a response surface regression model for cutting force and temperature generation at the insert edge was developed. For modeling and analysis, a design expert-expert version-10 tool has been used. The percentage contribution and $F$-value for the responses are shown in Table 3 . Since the established model has a ' $F$ ' value of 10.75 for cutting force and a ' $F$ ' value of 5.90 for temperature generation at the insert edge, it is more than adequate to predict temperature generation and cutting force $\left(F_{z}\right)$ at the insert edge depending on the ' $F$ ' test stage. The cutting force model's efficacy is confirmed by its $R^{2}$ value of 86.58 percent for $F_{z}$. As compared to depth of cut and cutting speed, the feed rate $F$-value is high $(F-77.096)$, meaning that it has a greater impact on the temperature at the insert edge. The cutting force model's efficacy is confirmed by its $R^{2}$ value of 77.98 percent for cutting force. Equations (2) and (3), respectively, are empirical equations for predicting cutting force and temperature at insert edge.

$$
\begin{aligned}
& F_{z}(N)=+375.84+25.82 * \mathrm{~S}+77 * f-6.10 * a_{p} \\
& \Theta\left({ }^{\circ} \mathrm{C}\right)=+492.24+41.32 * \mathrm{~S}+91.50 * f+47.74 * a_{p}
\end{aligned}
$$

\section{Experimental results and evaluation}

\subsection{Simulation of cutting force}

Table 4 displays the experimental results as well as the predicted values from the FEA model. In Figure 6, the experimental and predicted results are compared, showing a good agreement between the experimental 

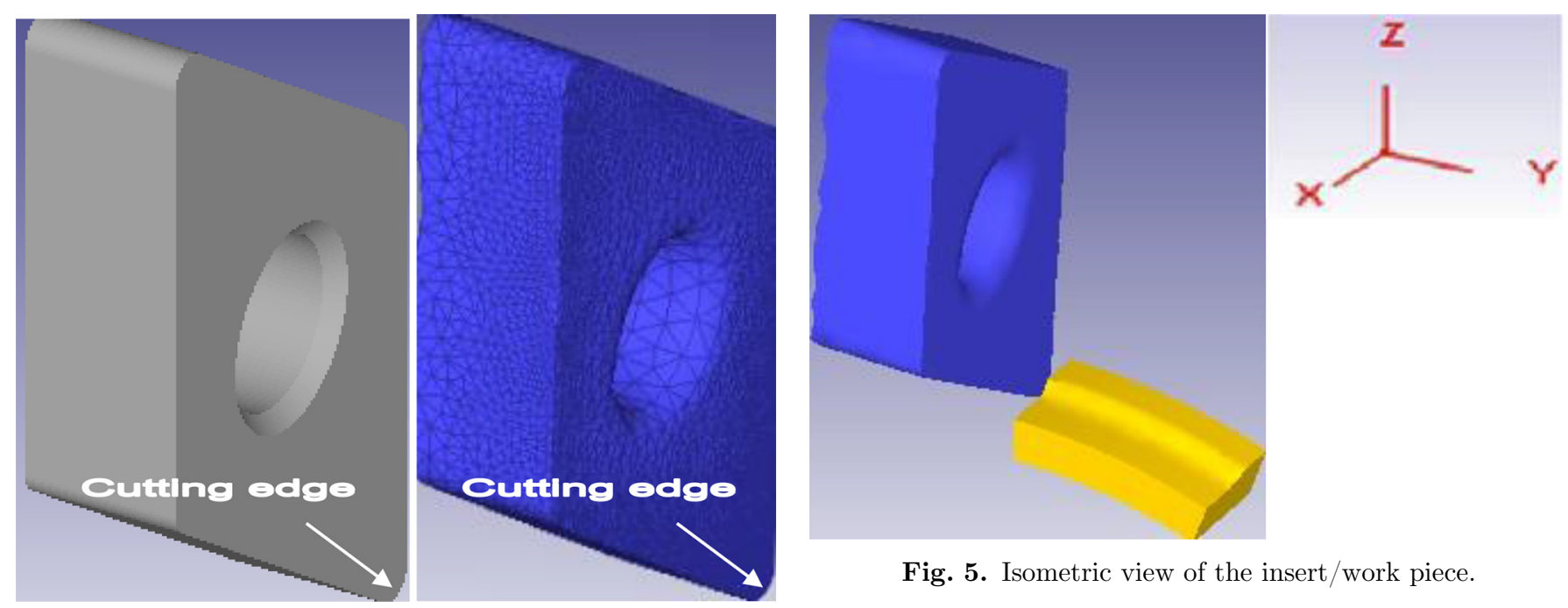

Fig. 5. Isometric view of the insert/work piece.

Fig. 4. View of the insert (a) without mesh, (b) with mesh.

Table 3. ANOVA (F-Value) table and Percentage contribution for the Responses.

\begin{tabular}{|c|c|c|c|c|c|c|}
\hline \multirow[t]{2}{*}{ S. no } & \multirow[t]{2}{*}{ Responses } & \multirow[t]{2}{*}{$\mathrm{R}-\mathrm{Sq}(\%)$} & \multicolumn{4}{|c|}{ F-Value } \\
\hline & & & Model & $\mathrm{S}-\mathrm{m} / \mathrm{min}$ & $\mathrm{f}-\mathrm{mm} / \mathrm{rev}$ & $\mathrm{a}_{\mathrm{p}-\mathrm{mm}}$ \\
\hline 1 & $\mathrm{Fz}$ & 86.58 & 10.75 & 3.35 & 28.71 & 0.1815 \\
\hline \multirow[t]{3}{*}{2} & $\theta\left({ }^{\circ} \mathrm{C}\right)$ & 77.98 & 5.90 & 2.52 & 11.92 & 3.27 \\
\hline & & & \multicolumn{4}{|c|}{$\%$ age Contribution } \\
\hline & & & $\mathrm{S}-\mathrm{m} / \mathrm{min}$ & $\mathrm{f}-\mathrm{mm} / \mathrm{rev}$ & $\mathrm{a}_{\mathrm{p}-} \mathrm{mm}$ & Error \\
\hline 1 & $\mathrm{Fz}-\mathrm{N}$ & 86.58 & $8.9896 \%$ & $77.096 \%$ & $0.487 \%$ & $13.424 \%$ \\
\hline 2 & $\theta\left({ }^{\circ} \mathrm{C}\right)$ & 77.98 & $11.102 \%$ & $52.493 \%$ & $14.386 \%$ & $22.017 \%$ \\
\hline
\end{tabular}

Table 4. Experimental condition and results.

\begin{tabular}{|c|c|c|c|c|c|c|c|c|c|c|}
\hline \multirow[t]{2}{*}{ S. no } & \multirow[t]{2}{*}{$\mathrm{S}(\mathrm{m} / \mathrm{min})$} & \multirow[t]{2}{*}{$\mathrm{f}(\mathrm{mm} / \mathrm{rev})$} & \multirow[t]{2}{*}{$\mathrm{a}_{\mathrm{p}}(\mathrm{m})$} & \multicolumn{2}{|c|}{ Exp., Results } & \multicolumn{2}{|c|}{ Predicted by RSM } & \multicolumn{3}{|c|}{ Predicted by FEA } \\
\hline & & & & $\mathrm{Fz}(\mathrm{N})$ & $\theta\left({ }^{\circ} \mathrm{C}\right)$ & $\mathrm{Fz}(\mathrm{N})$ & $\theta\left({ }^{\circ} \mathrm{C}\right)$ & $\mathrm{Fz}(\mathrm{N})$ & $\theta\left({ }^{\circ} \mathrm{C}\right)$ & $\begin{array}{l}\text { Effective } \\
\text { stress (MPa) }\end{array}$ \\
\hline 1 & 125 & 0.10 & 0.25 & 275 & 285 & 279 & 311 & 285 & 290 & 300 \\
\hline 2 & 125 & 0.20 & 0.40 & 383 & 425 & 350 & 444 & 380 & 430 & 480 \\
\hline 3 & 125 & 0.30 & 0.60 & 410 & 630 & 420 & 590 & 390 & 650 & 600 \\
\hline 4 & 175 & 0.10 & 0.40 & 310 & 385 & 308 & 407 & 315 & 390 & 390 \\
\hline 5 & 175 & 0.20 & 0.60 & 378 & 535 & 378 & 553 & 385 & 545 & 630 \\
\hline 6 & 175 & 0.30 & 0.25 & 415 & 590 & 467 & 549 & 410 & 610 & 655 \\
\hline 7 & 200 & 0.10 & 0.60 & 298 & 525 & 318 & 489 & 290 & 535 & 610 \\
\hline 8 & 200 & 0.20 & 0.25 & 422 & 565 & 407 & 485 & 415 & 555 & 635 \\
\hline 9 & 200 & 0.30 & 0.40 & 520 & 530 & 479 & 618 & 515 & 510 & 750 \\
\hline
\end{tabular}




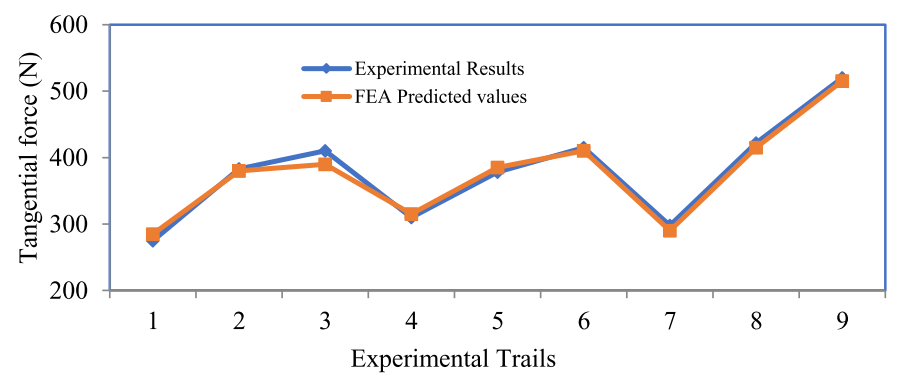

Fig. 6. Difference among experimental and simulated cutting force.

and FEA modeled results. It shows that the experimental and FEA model predicted values are strongly correlated, suggesting that the FEA model can be used to accurately predict the cutting force in turning AISI 304 stainless steel.

Figure $7 \mathrm{a}-\mathrm{c}$ shows few of the simulated cutting force. These findings were obtained with a shear friction factor of 0.6. The fine mesh has resulted in less fluctuation in the simulated outputs. The relative mesh was used to model the work piece and insert, with the scale ratio 5 taken into account. Different relative mesh sizes, such as 35000 , 40000, and 45000, were proposed to compare simulated values to experimental performance, and it was discovered that mesh size of 45000 was better for predicting output with the least amount of fluctuation. The DEFORM 3D solves time-dependent non-linear issues by producing a series of FEM responses at discrete time intervals. At every time increment, the temperatures, velocities, and other parameters of each node with in finite element mesh are determined on the basis on the thermo-mechanical properties including its work piece materials. The step controls, that include the beginning step number, the range of simulation steps, and the step increment to save [20].

The starting step number-1, the number of simulation steps-1000, as well as the step increment to save -20 were all considered. The tangential cutting force ranges from $275 \mathrm{~N}$ to $520 \mathrm{~N}$ depending on the experimental parameters levels, as shown in Figure $7 \mathrm{a}-\mathrm{c}$. As the feed rate rises, the magnitude of the tangential cutting force rises as well. The tangential force increases to $515 \mathrm{~N}$ as that of the feed rate and depth of cut rise, due to much more load generation at feed/depth of cut combination. Early research on turning AISI 316L stainless steel confirms this [15]. The rise the cutting force from $410 \mathrm{~N}$ to $515 \mathrm{~N}$, which corresponds to a $0.25 \mathrm{~mm}$ to $0.40 \mathrm{~mm}$ depth of cut, defines $0.25 \mathrm{~mm}$ as the critical depth of cut for turning AISI 304 steel. Figure 8 shows the 3D model graph obtained by RSM for cutting force and it is observed that, the cutting force increases as the level of feed increases followed by cutting speed and depth of cut.

\subsection{Simulation of temperature at insert edge}

Temperature generation has an effect on the machined surface and subsurface, and it's particularly critical in the case of AISI 304 steel surface integrity and tool wear. As a

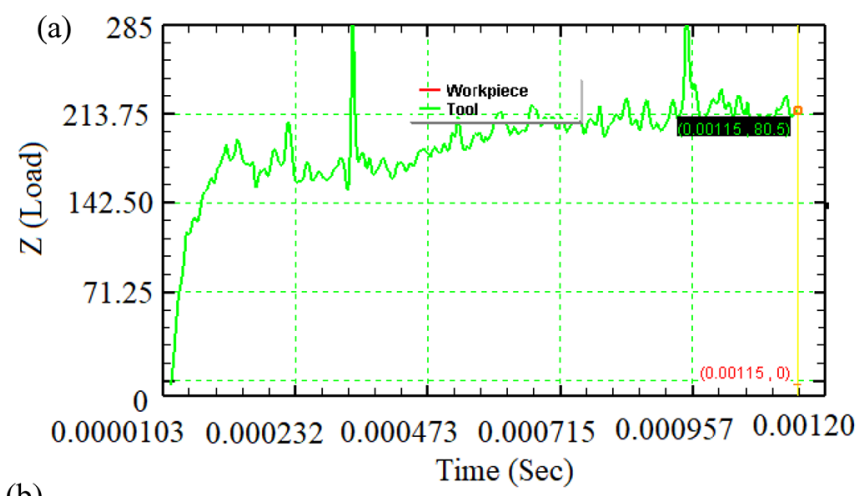

(b)

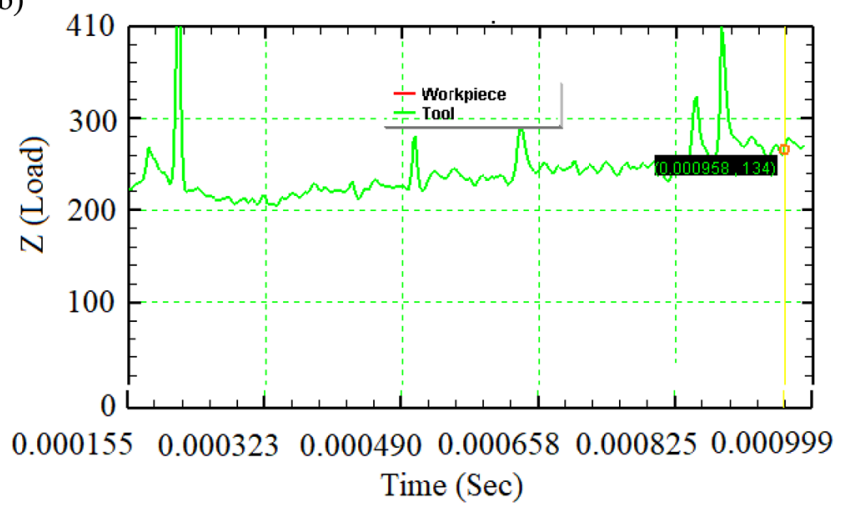

(c)

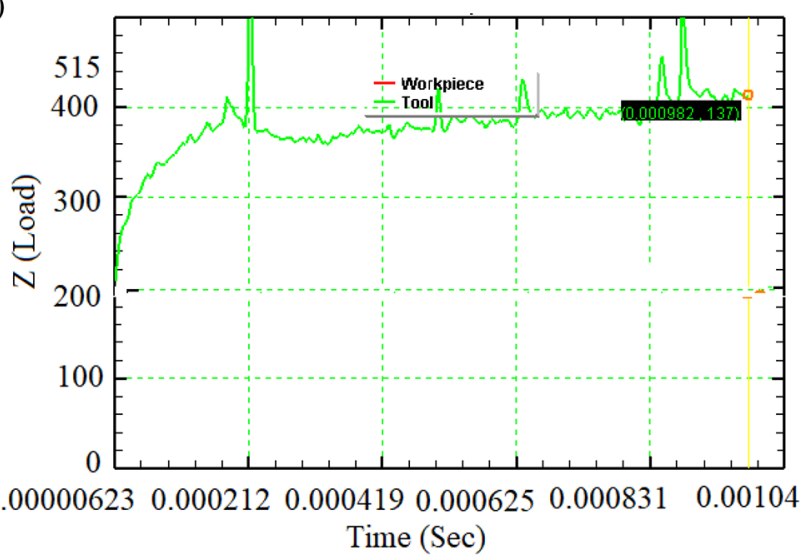

Fig. 7. $(\mathrm{a}-\mathrm{c})$ Simulated cutting force at various level of process parameters. (a) At $\mathrm{S}-125 \mathrm{~m} / \mathrm{min}, \mathrm{f}-0.10 \mathrm{~mm} / \mathrm{rev}, \mathrm{a}_{\mathrm{p}}-0.25 \mathrm{~mm}$, (b) at $\mathrm{S}-175 \mathrm{~m} / \mathrm{min}, \mathrm{f}-0.30 \mathrm{~mm} / \mathrm{rev}, \mathrm{a}_{\mathrm{p}}-0.25$. (c) $\mathrm{S}-, 200 \mathrm{~m} / \mathrm{min}$, $\mathrm{f}-0.30 \mathrm{~mm} / \mathrm{rev}, \mathrm{a}_{\mathrm{p}}-0.40 \mathrm{~mm}$.

result, it's important to look at how the temperature at the insert edge is induced during machining. The temperature at the insert edge was predicted using DEFORM 3D, and the modeled value was compared to experimental findings. As a result, the established model can be used effectively to identify the best process parameters in machining AISI 304 steel to obtain minimum temperature at insert edge. Figure 9 depicts some of the simulated temperature generation outputs for various process parameters using a shear friction factor of 0.6. The temperature at the cutting edge changes as the level of process parameters 


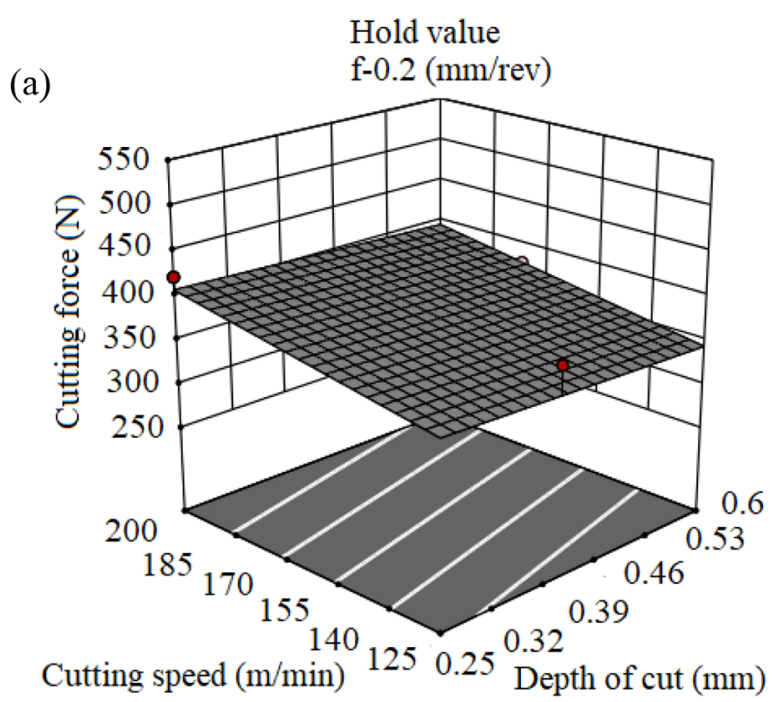

Hold value

(b)

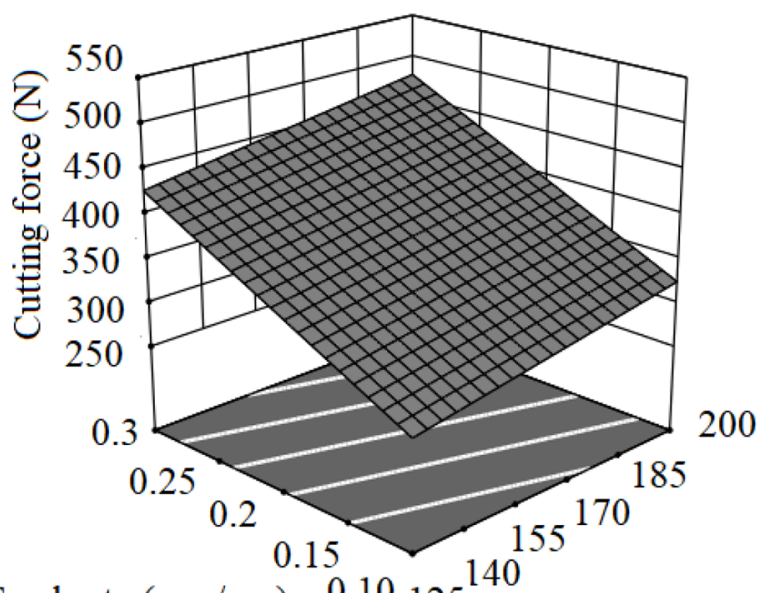

Feed rate $(\mathrm{mm} / \mathrm{rev}) \quad 0.10125^{140}$ Cutting speed $(\mathrm{m} / \mathrm{min})$

(c)

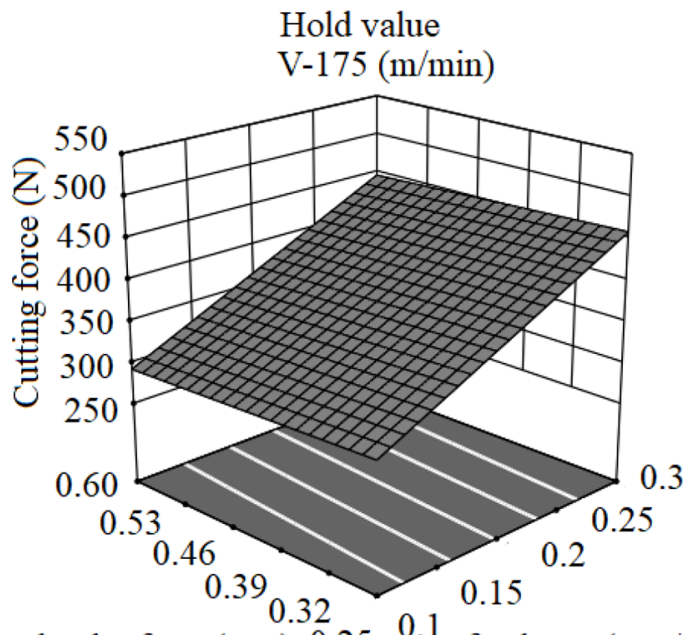

depth of cut (mm) $0.25{ }^{0.1}$ feed rate ( $\left.\mathrm{mm} / \mathrm{rev}\right)$

Fig. 8. 3D model-cutting force. (a) Interaction effect of depth of cut and cutting speed. (b) Interaction effect of cutting speed and feed rate. (c) Interaction effect of feed rate and depth of cut. (a)

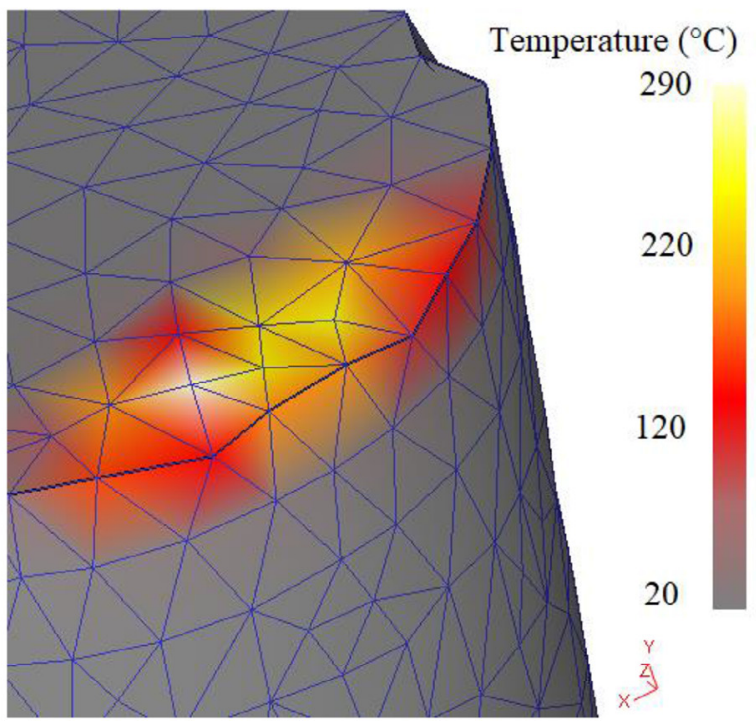

(b)
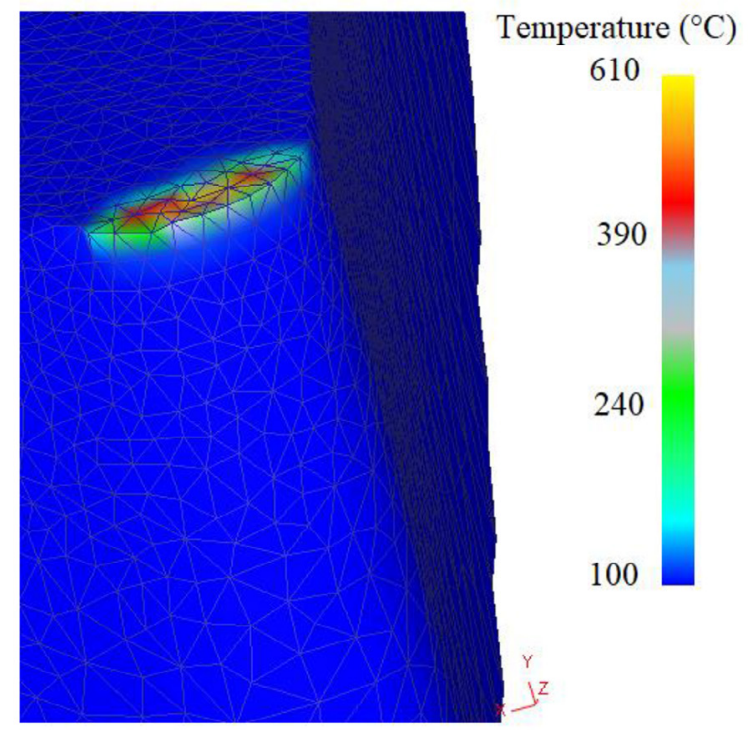

610

390

240

100

(c)

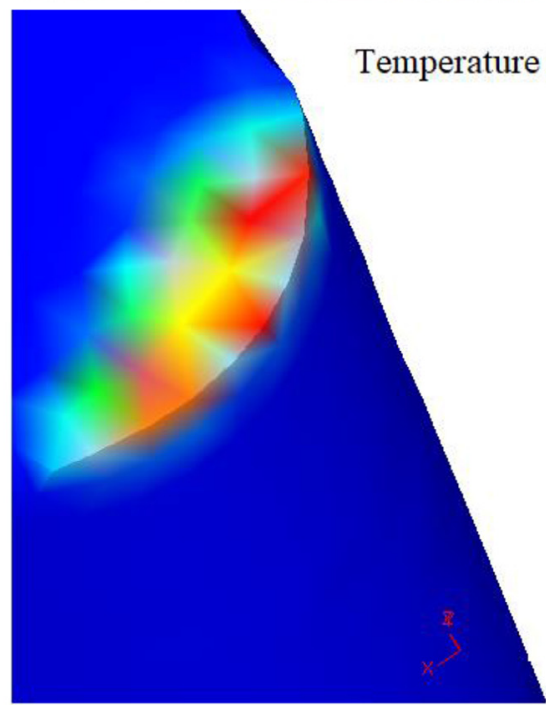

650

400

250

100

Fig. 9. (a-c) Simulated temperature at cutting edge for various level of process parameters. (a) at $\mathrm{S}-125 \mathrm{~m} / \mathrm{min}, \mathrm{f}-0.10 \mathrm{~mm} / \mathrm{rev}$, $\mathrm{a}_{\mathrm{p}}-0.25 \mathrm{~mm}, \quad$ (b) at $\mathrm{V}-175 \mathrm{~m} / \mathrm{min}, \mathrm{f}-0.30 \mathrm{~mm} / \mathrm{rev}, \quad \mathrm{a}_{\mathrm{p}}-0.25$. (c) $\mathrm{V}-, 200 \mathrm{~m} / \mathrm{min}, \mathrm{f}-0.30 \mathrm{~mm} / \mathrm{rev}$, ap- $0.40 \mathrm{~mm}$. 
changes. As process parameters such as feed rate, cutting speed and depth of cut increases, the temperature at the edge rises. This is consistent with previous studies on stainless steel 304 in turning process [17]. Figure 9a, b shows that at $200 \mathrm{~m} / \mathrm{min}, 0.30 \mathrm{~mm} / \mathrm{rev}$, and $0.40 \mathrm{~mm}$, a higher temperature of $650^{\circ} \mathrm{C}$ was induced at the cutting edge.

Temperature generation in machining is crucial because it affects tool life, part efficiency, chip morphology, and other factors. As a result, while machining, temperature generation is measured and investigated the effects of machining parameters on temperature generation [21]. When turning AISI 304 steel, which has a minimum thermal conductivity of $16.2 \mathrm{~W} / \mathrm{m} \mathrm{K}$, a large amount of temperature is observed at the insert edge at greater depths of cut, higher feed rates and lower cutting speeds. It may also be that at low cutting speeds, chip thickness increases and chip curl radius decreases, resulting in increased temperature generation [14]. The feed rate is much influenced on temperature at edge followed by depth of cut and cutting speed and is depicts in the 3D graph developed by RSM as shown in the Figure 10.

Figure $11 \mathrm{a}-\mathrm{h}$ shows percentage error observed among the experimental and predicted values using RSM and FEA for the responses such as cutting force and temperature generation at insert edge. The predicted values for cutting force and temperature at insert edge using RSM and FEA are compared with experimental values. The average percentage error among experimental and predicted values for cutting force and temperature at insert edge using RSM was found to be $4.55 \%$ and $7.74 \%$ respectively. The average percentage error among experimental results and predicted values for cutting force and temperature at the insert edge using FEA was found to be $2.10 \%$ and $2.18 \%$ respectively. Therefore, the model developed by FEA agreed well with the experimental results and as a result, the developed FEA model can be used to forecast the responses such as cutting force and temperature at insert edge reliably.

\subsection{Stress's effects at the tool-work interface}

As the insert edge enters the work material in machining, shear deformation is caused, and the degree of deformation varies as the level of process parameters changes. Figure 12 depicts the distribution of successful stress in turning AISI 304 steel, as simulated using FEM at various process parameter stages. As both the feed rate as well as cutting speed rise the magnitude of the effective stress generally increases, as shown in Figure 12a-c. A upper limit of $750 \mathrm{MPa}$ was measured at a depth of cut of $0.40 \mathrm{~mm}$, a feed rate of $0.30 \mathrm{~mm} / \mathrm{rev}$ and cutting speed of $200 \mathrm{~m} / \mathrm{min}$. Increase in total cutting speed from 125 to $200 \mathrm{~m} / \mathrm{min}$ resulted in even more deformation at the tool wear contact area, whereby strain rate and chip strain were reported to be significant, resulting in far more strain up to $5.465 \mathrm{~mm} / \mathrm{mm}$, as can be seen in Figure 12.

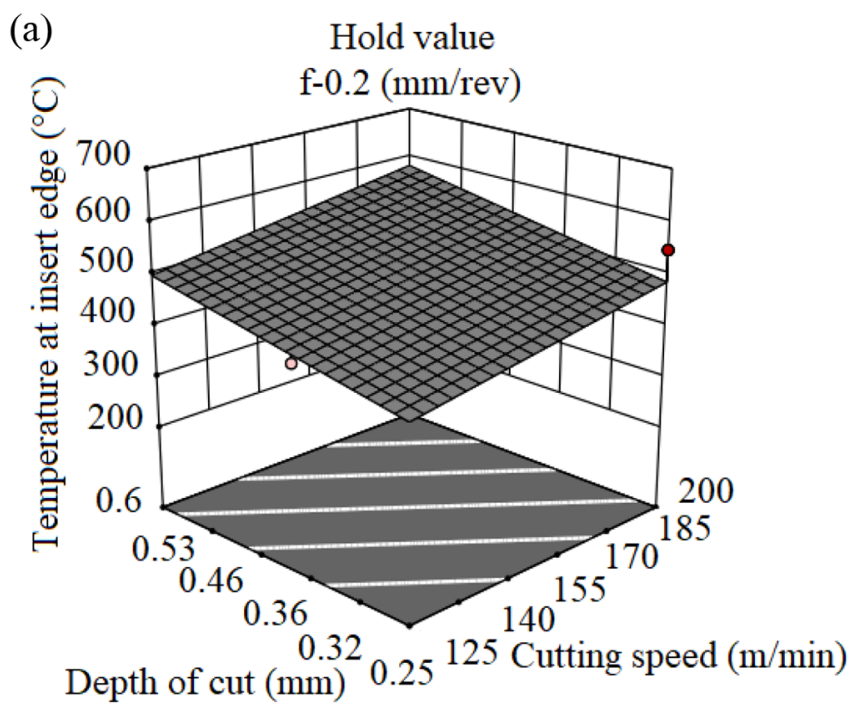

(b)

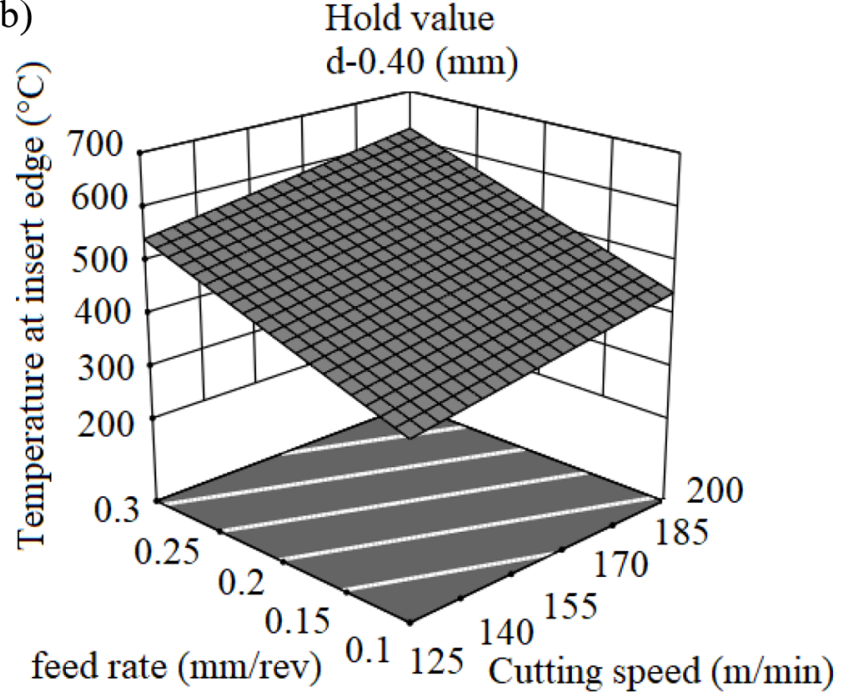

(c)

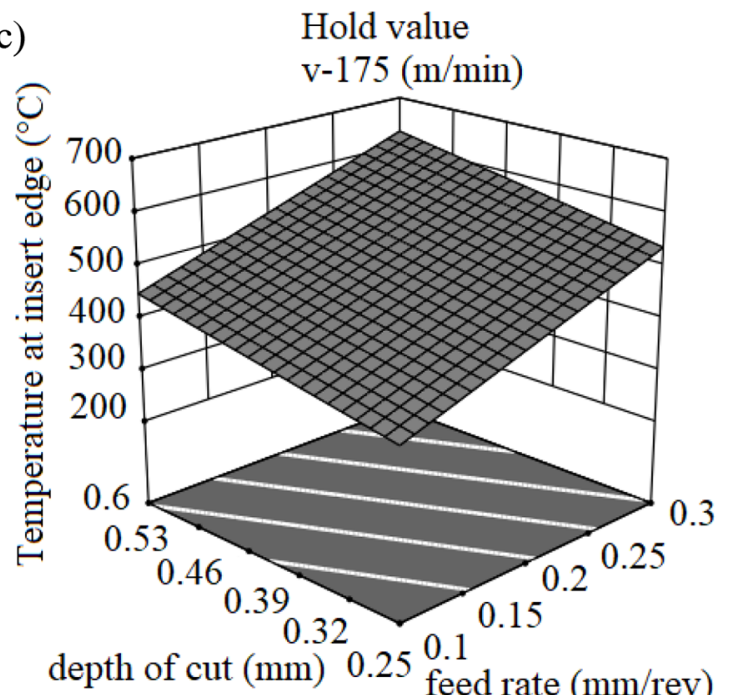

Fig. 10. 3D model-temperature at cutting edge. (a) Interaction effect of depth of cut and cutting speed. (b) Interaction effect of cutting speed and feed rate. (c) Interaction effect of feed rate and depth of cut. 


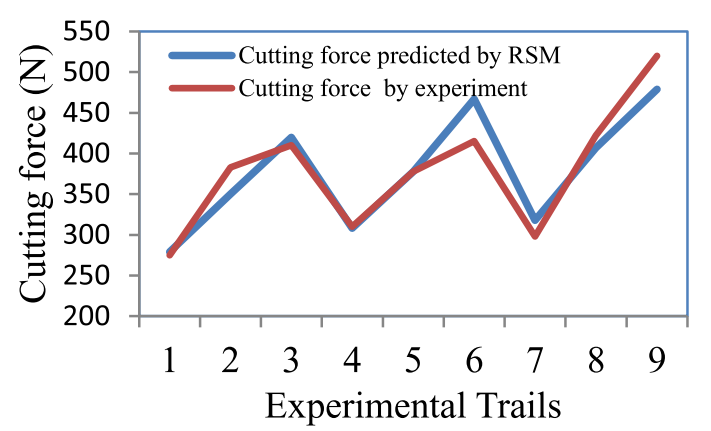

Fig. 11 (a)

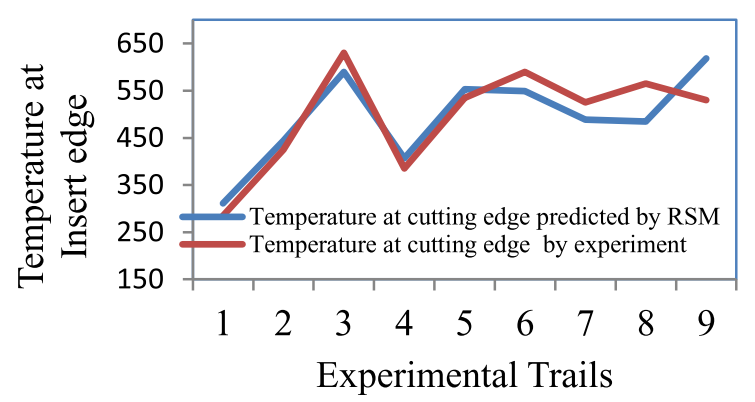

Fig.11 (c)

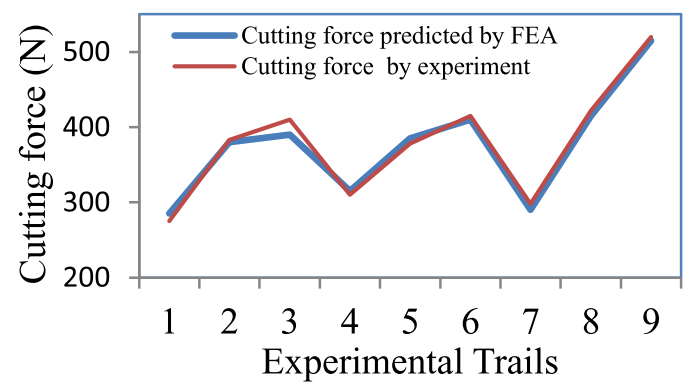

Fig.11 (e)

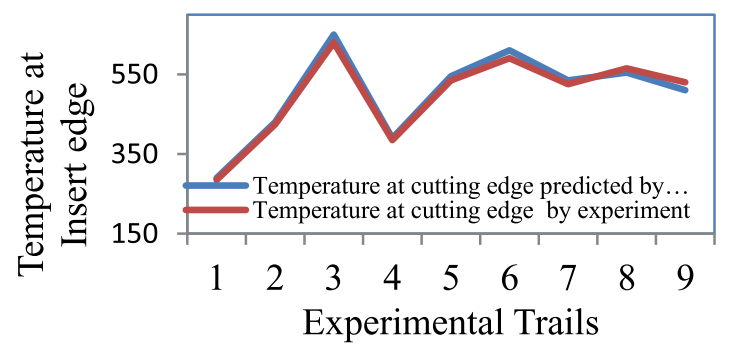

Fig.11 (g)

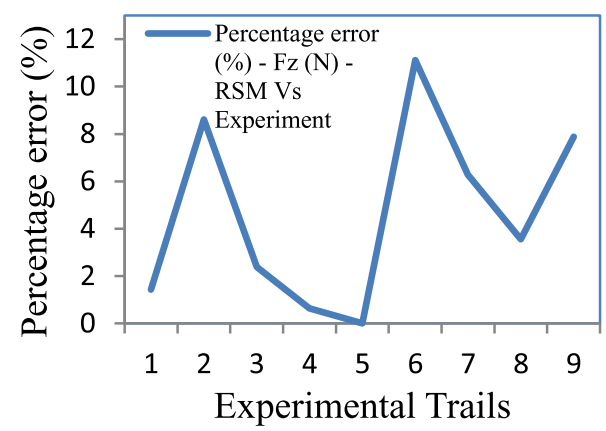

Fig.11 (b)

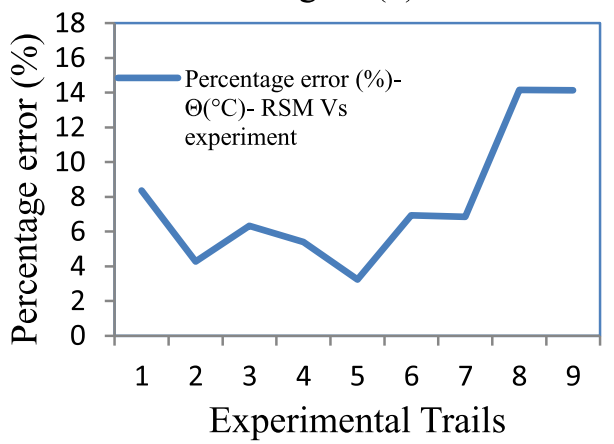

Fig.11 (d)

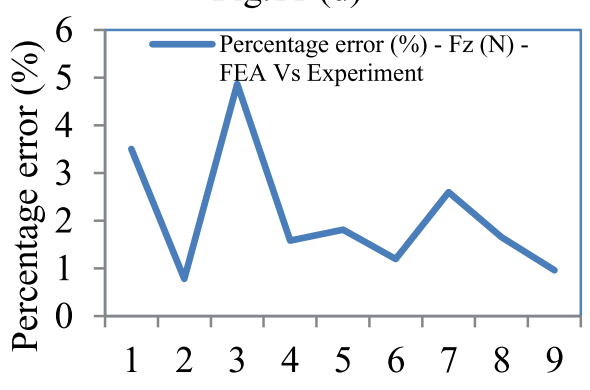

Experimental Trails

Fig.11 (f)

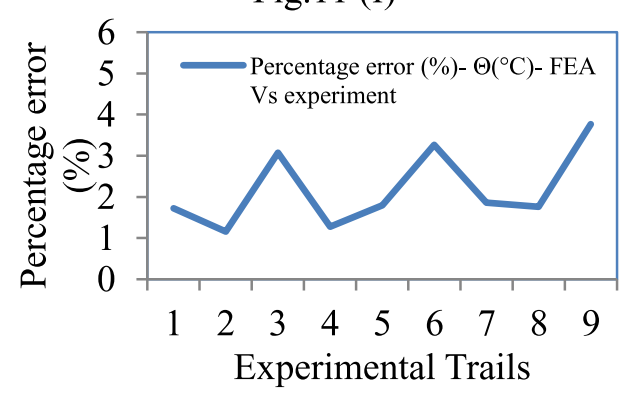

Fig.11 (h)

Fig. 11. $(\mathrm{a}-\mathrm{h})$ Percentage error: experimental and predicted values by RSM and FEA. (a) Cutting force: predicted by RSM vs experimental values. (b) Percentage error - cutting force: predicted by RSM vs experimental values. (c) Temperature at insert edge: predicted by RSM vs experimental values. (d) Percentage error - temperature at insert edge: predicted by RSM vs experimental values. (e) Cutting force: predicted by FEA vs experimental values. (f) Percentage error - cutting force: predicted by FEA vs experimental values. (g) Temperature at insert edge: predicted by FEA vs experimental values. (h) Percentage error - temperature at insert edge: predicted by FEA vs experimental values. 
(a)

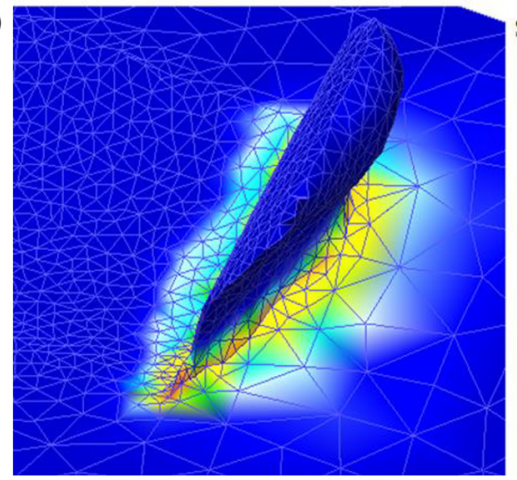

Stress Effective (Mpa) 300

200

100

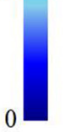

(b)

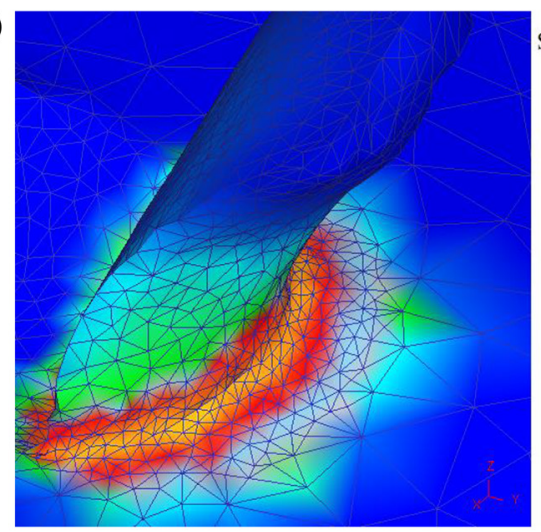

Stress effective (Mpa)

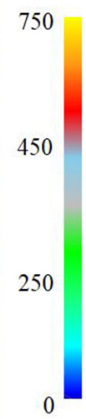

(c)

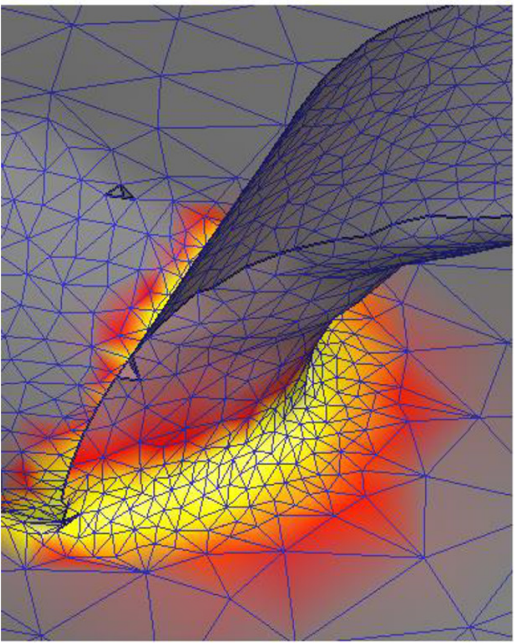

Stress effective (Mpa)

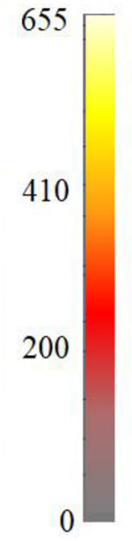

Fig. 12. Effective stress distribution at various level of machining parameters.

\section{Conclusions}

The following conclusions were drawn from the results of the 3D Finite Element Analysis simulation and experiments in turning AISI 304 steel with a PVD coated cemented carbide insert.

- The developed model through FEA-DEFORM 3D would be more effective, comparing to RSM, for predicting the cutting force and temperature at insert edge, prior to the actual experiment performed and therefore, the wastage cost occurred owing to unidentified impact of the process parameters could be eliminated in turning the AISI 304 stainless steel.

- The \%error between the simulated and experimental values cutting force results and temperature at insert edge is found to be within $2.10 \%$ and $2.18 \%$ respectively. As a result, the FEA model can be used effectively to evaluate the cutting force and temperature at insert edge in turning AISI 304 stainless steel.

- As the level of processing parameters differs, the cutting force tends to vary around $285 \mathrm{~N}-515 \mathrm{~N}$. The critical depth of cut in turning AISI 304 steel by such a steep increase in cutting force from $410 \mathrm{~N}$ to $515 \mathrm{~N}$ at depth of $0.25 \mathrm{~mm}-0.40 \mathrm{~mm}$ respectively was observed.

- The maximum temperature at insert edge of $650{ }^{\circ} \mathrm{C}$ was obtained at $0.40 \mathrm{~mm}$ depth of cut, $0.30 \mathrm{~mm} / \mathrm{rev}$ feed rate and $200 \mathrm{~m} / \mathrm{min}$.

- At a cutting speed of $200 \mathrm{~m} / \mathrm{min}$, a highest value of $750 \mathrm{MPa}$ was measured. Because of relatively higher deformation, the chip curls further at the tool-work contact area, which could be responsible for the increase in the strain rate as when the cutting speed increases from 125 to $200 \mathrm{~m} / \mathrm{min}$.

- Further, the 3D-FEA model developed in this study can be effectively utilized to simulate the chip formation and tool wear as these directly affect the integrity of the machined surface in turning AISI 304 steel.

Acknowledgments. This work is partially funded by Centre for Materials Research, Chennai Institute of Technology vide funding number is CIT/CMR/2021/005.

\section{References}

1. C. Ezilarasan, V.S. Senthil Kumar, A. Velayudham, Theoretical predictions and experimental validations on machining the Nimonic C-263 super alloy, Simul. Model. Practice Theory 40 (2014) 192-207

2. M. Nagaraj, A. John Presin Kumar, C. Ezilarasan, R. Betala, Finite element modeling in drilling of Nimonic C-263 alloy using deform-3D, CMES 118 (2019) 679-692

3. A. Yildız, A. Kurt, S. Yagmur, Finite element simulation of drilling operation and theoretical analysis of drill stresses with the deform-3D, Simul. Model. Practice Theory 104 (2020) 102153

4. A. Tzotzis, C. Garcia-Hernández, J.-L. Huertas-Talon, P. Kyratsis, FEM based mathematical modeling of thrust force during drilling of Al7075-T6, Mech. Ind. 21 (2020) 415

5. Y. Su, G. Zhao, Y. Zhao, J. Meng, C. Li, Multi-objective optimization of cutting parameters in turning AISI 304 austenitic stainless steel, Metals 10 (2020) 217

6. A. Elkaseer, A. Abdelaziz, M. Saber, A. Nassef, FEM-based study of precision hard turning of Stainless Steel 316L, Materials 12 (2019) 2522

7. K. Leksycki, E. Feldshtein, J. Lisowicz, R. Chudy, R. Mrugalski, Cutting forces and chip shaping when finish turning of 17-4 PH stainless steel under dry, wet, and MQL machining conditions, Metals 10 (2020) 1187

8. Y. Xu, P. Zou, Y. He, S. Chen, Y. Tian, X. Gao, Comparative experimental research in turning of 304 austenitic stainless 
steel with and without ultrasonic vibration, J. Mech. Eng. Sci. (2016) 1-17

9. M. Sadeghifar, R. Sedaghati, W. Jomaa, V. Songmene, Finite element analysis and response surface method for robust multi-performance optimization of radial turning of hard 300M steel, J. Adv. Manufactur. Technol. 94 (2018) 2457-2474

10. D. Boing, A. José de Oliveira, R. Bertrand Schroeter, Evaluation of wear mechanisms of PVD and CVD coatings deposited on cemented carbide substrates applied to hard turning, Int. J. Adv. Manuf. Technol. 106 (2020) 1-11

11. A.K. Parida, P.V. Rao, S. Ghosh, Numerical analysis and experimental investigation in the machining of AISI 316 steel, Sadhana 45 (2020) 1

12. M. Agmell, A. Ahadi, O. Gutnichenk, J.-E. Stahl, The influence of tool micro-geometry on stress distribution in turning operations of AISI 4140 by FE analysis, J. Adv. Manuf. Technol. 89 (2020) 3109-3122

13. M. Sadeghifar, R. Sedaghati, W. Jomaa, V. Songmene, A comprehensive review of finite element modeling of orthogonal machining process: chip formation and surface integrity predictions, Int. J. Adv. Manuf. Technol. 96 (2018) 3747-3791

14. A. Yildiz, A. Kurt, S. Yagmur, Finite element simulation of drilling operation and theoretical analysis of drill stresses with the deform 3D, Simul. Model. Practice Theory 104 (2020) 102153

15. R. Nur, M.Y. Noordin, S. Izman, D. Kurniawan, Machining parameters effect in dry turning of AISI 316L stainless steel using coated carbide tools, Proc. Inst. Mech. Eng. E 231 (2017) 676-683

16. A. Ay, Optimizations of machining parameters in turning AISI 304L stainless steel by the grey-based Taguchi method, Acta Phys. Pol. A 131 (2017)

17. M. Hasan Tanvir, M. Afzal Hussain, M. Towfiqun Rahman, S. Ishraq, K. Zishan, S.K. Tashowar Tanzim Rahul, M. Ahsan Habib, Multi-objective optimization of turning operation of stainless steel using a hybrid whale optimization algorithm, J. Manuf. Mater. Process. 64 (2020) 1-14

18. Y. Zhou, H. Sun, A. Li, M. Lv, C. Xue, J. Zhao, FEM simulation-based cutting parameters optimization in machining aluminum-silicon piston alloy ZL109 with PCD tool, J. Mech. Sci. Technol. 33 (2019) 3457-3465

19. L.A. Denguira, J.C. Outeiro, J. Rech, G. Fromentin, V. Vignal, R. Besnard, Friction model for tool/work material contact applied to surface integrity prediction in orthogonal cutting simulation, Proc. CIRP 58 (2017) $578-583$

20. A. Kumar Parida, K. Maity, Analysis of some critical aspects in hot machining of Ti-5553 super alloy: experimental and FE analysis, Defence Technol. 15 (2019) 344-352

21. M. Alabdullah, A. Polishetty, J. Nomani, G. Littelfair, Experimental and finite element analysis of machinability of AL-6XN super austenitic stainless steel, Int. J. Adv. Manuf. Technol. 91 (2017) 501-516

Cite this article as: A. Mathivanan, M.P. Sudeshkumar, R. Ramadoss, Chakaravarthy Ezilarasan, Ganesamoorthy Raju, V. Jayaseelan, Finite element simulation and regression modeling of machining attributes on turning AISI 304 stainless steel, Manufacturing Rev. 8, 24 (2021) 